\title{
The Impact of Veganism/Vegetarianism on Animal Welfare Policy
}

\author{
Lama El Azrak \\ School of Public Administration \\ Dalhousie University \\ Lama.ElAzrak@dal.ca \\ Sylvain Charlebois \\ School of Public Administration \\ Dalhousie University \\ Sylvain.charlebois@dal.ca
}

Received: May 23, 2020

Accepted: August 28, 2020

Published: September 28, 2020

doi:10.5296/jpmr.v6i2.17750

URL: https://doi.org/10.5296/jpmr.v6i2.17750

\begin{abstract}
Veganism/vegetarianism is gaining popularity as a food trend, which may generate a high interest in animal welfare. This paper analyzes the motives behind veganism/vegetarianism and its potential impacts on animal welfare policies. It also examines various policy options attempting to improve animal welfare. A qualitative analysis was conducted for this paper. This included a literature review, where 14 articles were selected. The findings showed that while there does not seem to be a clear causation affect between veganism/vegetarianism and animal welfare policies, there are definitely potential impacts that may be more evident in future years and that should be addressed by policymakers and industry leaders.
\end{abstract}

\section{Introduction}

Animal welfare is one of the most controversial topics regarding modern livestock agriculture. (Lusk, 2011). Many consumers want to amend current production practices and have resorted to plant-based diets to reduce their meat consumption. Plant-based diets have emerged as a rising food trend. Vegetarians and vegans make up approximately $10 \%$ of Canadians (Flanagan, 2018). The vegetarian diet excludes meat products, whereas the vegan diet also excludes any animal by-products e.g. milk, honey, eggs, etc. (Charlebois, 2018). These diets, however, may be expressed in varied ways depending on the individual. The number of 
vegetarians in Canada went up by about $60 \%$ in the last 15 years, accounting for 2.3 million vegetarians as of 2018 (Flanagan, 2018). Additionally, there are 850,000 individuals in Canada who identify as vegans (Flanagan, 2018). Furthermore, individuals who are under the age of 35 are three times more likely to identify as vegetarians and vegans than ages 49 and above (Flanagan, 2018). This indicates that plant-based diets are more appealing to the younger generation, it also alludes to a surge in plant-based diets as generations become older and play more powerful roles in society. On the other hand, meat consumption has also risen in the last 50 years (Bonnet et al., 2020). This is due to industrial farming becoming more popular post World War II. Given these two clashing phenomenons, it is interesting to analyze their impact on policy, particularly animal welfare policy. Although not all plant-based diet followers choose to follow the aforementioned diet because of animal welfare reasons, nevertheless, there is a rising global interest around animal welfare in industrial farming. This may be attributed to the growth in scientific knowledge about animal emotion and lives, as well as general knowledge on industrial farming and animal farming conditions. Rising veganism and vegetarianism is often associated with the increasing concern for animal welfare in the food industry (Bonnet et al., 2020; Ruby, 2012; The Economist, 2018). This paper assesses the impact of veganism/vegetarianism on animal welfare policy. It examines the rationale and drivers of following a plant-based diet to understand the perspectives of vegans/vegetarians on animal welfare. It also assesses the various jurisdictions over animal welfare policy in Canada and different policy instruments to address animal welfare concerns.

\section{Methods}

A qualitative analysis approach was used for this paper. A literature review was conducted, focusing on the motives of vegans and vegetarians, the history and current status of animal welfare policy jurisdiction in Canada, and the policy options for addressing animal welfare. The findings were then analyzed in the discussion portion of the paper.

The search for the literature was limited to inclusion criteria. It was important that the articles made some form of reference to farm animal welfare because this paper relates consumers' eating habits, in this context vegans and vegetarians, to animal welfare policy in the food sector. Furthermore, when it came to conducting search for literature on the jurisdictions over animal welfare policy, it was essential to limit the articles to the Canadian framework. In this context, jurisdictions over animal welfare policy means the authoritative decisionmakers regarding welfare policy in Canada.

The first database searched for this review was Scopus. The search terms used were: "animal welfare", "policy", "vegetarian", "vegan", "food trends", "plant-based", "impact" "food sector", "agriculture", "farming”, "animal well-being”. These terms were used in different combinations to generate relevant results, judged by an initial title scan of the first few results. Upon determining relevancy of the results generated from a combination of the search terms, a scan of the titles was conducted. Six articles were selected for an abstract review out of 39 articles that were generated. After reviewing the abstracts, three articles were selected for a more thorough analysis and were included in the literature review. A similar search strategy was conducted on Econlit, Novanet, and Google Scholar, resulting in 10 articles being 
selected for the literature review. Finally, a search of animal welfare acts in Canada using the Canadian government website was also conducted. This brought the total number of articles selected for the literature review up to 14 articles.

\section{Literature Review Findings}

\subsection{The Rise and Motives of Vegans/Vegetarians}

Although vegetarians and vegans make up only a small portion of the population, there is no doubt that they have an influence on the food sector as consumers and on food policy as active citizens. For example, the number of vegan restaurants in Germany went up to 122 in 2015 from 75 in 2013 (Janssen et al., 2016). In order to effectively assess the impact that vegetarians and vegans have on societal issues, it is crucial to understand the different motives for following a plant-based diet. It is also important to recognize the attitude of vegans/vegetarians towards farm animal welfare. These understandings will aid researchers and policymakers to estimate future trends and develop effective animal welfare policies. Throughout this literature review and paper, the term 'vegan/vegetarian' will be used to generally signify vegans and/or vegetarians and vice versa. However, only one of these terms, either vegan or vegetarian, will be used when attempting to make a distinction or when an article that is being assessed only focuses on one of these diets.

A study by Janssen et al. (2016) noted that the number of vegan consumers and demand for vegan food continues to increase substantially. The study conducted interviews with vegan consumers about their motives for following the diet. Approximately $89.7 \%$ of respondents followed a vegan diet because of animal-related motives, this included animal welfare, animal agriculture and/or animal rights (Janssen et al., 2016). The second and third most popular reasons were personal well-being and/or health and environmental protection respectively. Furthermore, $10 \%$ attributed social justice, specifically related to human rights, as their motive for being vegan, and 5\% attributed their opposition to the food industry as their motive (Janssen et al., 2016). The majority of those surveyed mentioned that they do not believe animal welfare can be achieved in the agriculture sector, thus advocating for individuals to refrain from consuming animal products (Janssen et al., 2016).

Herzog et al. (2009) surveyed individuals, including animal activists, promoters of animal use, and those who are not part of animal-related movements, to assess their sensitivity to visceral disgust and animal welfare. The interesting component regarding this study is that they also surveyed participants on their views about activism. The survey found that animal activists were more sensitive to visceral disgust and that sensitivity was positively associated with attitudes regarding animal welfare (Herzog et al., 2009). However, the most intriguing finding was that almost half of the animal activists were meat eaters, whereas half of the vegetarians did not identify as animal activists (Herzog et al., 2009). This finding shows that while veganism/vegetarianism may appear as an act of protest, the individuals who follow these diets may not consider themselves activists. The attitude towards activism may play a role in the level of impact that vegans/vegetarians create on animal welfare policies.

Fox (2013) states that although there are individuals who follow a vegan diet for health or hedonistic reasons, ethical concerns typically develop later on. Fox (2013) highlights reasons 
for why individuals adopt a vegetarian or vegan diet. The reasons fall under ethical concerns and contain factors such as the caring approach, nonviolence as a philosophy, and justice (Fox, 2013). The caring approach is a natural feeling that leads individuals towards wanting to remove suffering from an entity, even if it is not directly related to one's own suffering (Fox, 2013). The nonviolence philosophy focuses on actively trying to remove harm from the world in order to enhance peacefulness in society (Fox, 2013). Lastly, justice lies behind the idea that the suffering animals have to endure outweighs the pleasure that humans receive from eating meat (Fox, 2013). These reasons are important to explore because they present the perspectives of vegans/vegetarians and allow policymakers to understand and target these perspectives when designing animal welfare policy.

\subsection{Evolutions in Animal Welfare Policies}

Animal welfare is defined as the well-being of animals, and arguably includes the care of animals as well (Bradley \& MacRae, 2011). Including the term 'care' views animal welfare from the perspective of the caregiver, since animal welfare policies may impact the behaviour of the caregiver e.g. farmer, producer, etc. (Bradley \& MacRae, 2011). Some measures used by animal scientists to assess animal welfare include rate of injuries, level of stress hormones, and transport time (Bonnet et al., 2020; Broom, 2014). Given the broadness of the term 'animal welfare', Canada does not have one consistent and overarching animal welfare policy.

Until the 1950s animal agriculture consisted of traditional methods involving manual labour where farm animals were kept outdoors or in semi-outdoor spaces (Fraser, 2010). After World War II, farming shifted more towards automated and technological methods of products. 'Confinement' animal production became popular (Fraser, 2010). Confinement involved animals being kept within indoor or semi-indoor environments, where routine farming tasks can be conducted through technological means (Fraser, 2010). Indoor environments limit animals from being able to move freely and to perform regular behaviours (Fraser, 2010). For instance, pigs are kept in group pens that are usually indoors or semi-indoors. The pens are usually just large enough for the pigs to lie down, but not to roam around (Fraser, 2010). However, animal welfare was a concern for Canadians long before the rise of industrial farming. In 1869, the Cruelty to Animals Act was passed in Canada, an act that was pushed forward by organizations such as the Canadian Society for the Prevention of Cruelty to Animals (Ingram, 2017). The act promoted the development of NGOs to ensure animal welfare standards were maintained in Canada (Ingram, 2017). It also legitimized the concern for animal welfare because it allowed the state to intervene in cases of animal cruelty. Despite the Government's early commitment to animal welfare, Canada's standards for animal welfare are considered relatively weak compared to European jurisdictions (Bradley \& MacRae, 2011).

Currently Canada's animal welfare jurisdictions consist of legislated laws related to the treatment of farm animals and voluntary codes (Bradley \& MacRae, 2011). The laws mostly consist of prohibitions from causing distress to animals (Bradley \& MacRae, 2011). These laws are found in the Criminal Code of Canada and in provincial animal welfare statutes. There are also laws pertaining to the treatment of livestock animals in various federal 
regulations and acts such as the Safe Food For Canadians Regulations and the Health of Animals Act (Government of Canada, 2020). The voluntary codes, however, contain more detailed farm animal welfare practices such as space requirements and barn lighting (Bradley $\&$ MacRae, 2011). The Canadian Federation of Humane Societies started the development of the codes, but the Canadian Agri-Food Research Council (CARC) took over the codes in 1994 (Bradley \& MacRae, 2011). The government's support to the advancement of these codes was minimal, and progress was slow. In 2005, the National Farm Animal Care council became in charge of the codes (Bradley \& MacRae, 2011). Based off these codes, other organizations have also formed their own standards. For instance, several restaurants and chain restaurants have developed animal welfare purchasing standards. (Bradley \& MacRae, 2011). Furthermore, Chicken Farmers of Canada and the Canadian Pork Council both created certification programs that are based on the codes (Bradley \&d MacRae, 2011). It is essential to note that these codes were not designed to maximize animal welfare, but to standardize industry practices. These codes can be used as an educational tool for activists and policymakers to assess industry standards. Additionally, it is interesting to note that many of these voluntary codes and standards are being set by private sector organizations. These organizations may have to reassess their standards based on the changes in their consumers' behaviours. As mentioned, veganism/vegetarianism is becoming more popular and the private sector will soon enough experience the impact of this phenomena. As a result, the private sector will have to change behaviours to meet demand changes.

\subsection{Animal Welfare Policy Options}

One of the reasons that veganism/vegetarianism may have an impact on animal welfare policy is the economic influence that vegan/vegetarian consumers may cause. It is important to address the vegan/vegetarian trend from the perspective of economics because it may lead to the realization that government intervention is necessary and that addressing animal welfare policy in the next few years may be urgent.

An article by Lusk et al. (2011) examines the ability to conduct a cost-benefit analysis on animal welfare policies. The article states that consumer economics play a vital role in animal welfare policy, however it also may hinder the success of a policy cost-benefit analysis. This is because consumers are not sufficiently aware about how animal are raised in farms (Lusk et al., 2011). The authors state that most consumers have a generally positive view regarding animal agriculture. Consumers believe that more farm animals roam in free-range type environments than the reality. Lusk et al. (2011) also state that the majority of consumers are generally willing to pay more in order to reduce inhumane farming practices. Bennett (1997) conducted a survey to find out consumers' view on farm animal welfare and their willingness-to-pay for legislation that would phase out the use of cages in egg production by 2005 in the European Union. The results showed that 41\% and 45\% were "very concerned" and "somewhat concerned" respectively about the mistreatment of animals in the production process (Bennett, 1997). Furthermore, 61\% avoided or purchased specific animal products because of their animal welfare concerns (Bennett, 1997). Finally, 79\% supported the legislation of phasing out cages in egg production (Bennett, 1997). However, not all consumers are usually informed about these production practices, thus, it is difficult to 
measure the likelihood of consumers to support an animal welfare policy. Bonnet et al. (2020) states that informational policy instruments can be used to raise awareness regarding the characteristics of animal products. Informational instruments attempt to balance the information asymmetry that the market is experiencing, thus, driving consumers to more animal-welfare friendly products (Bonnet et al., 2020). This where vegans/vegetarians can play a role. They can raise awareness about animal welfare issues, hence increasing compassion amongst meat and nonmeat eaters. However, vegans/vegetarians can only make a relative impact if there are enough of them that advocate for the causes that drove them towards a plant-based diet.

One factor that should be acknowledged when developing animal welfare policies is the unlikelihood of animal welfare concerned vegans/vegetarians achieving their ideal activism goal, which is to eliminate the consumption of meat. Animal agriculture and meat consumption are part of a variety of important and powerful industries that benefit from these activities. McInerney (2004) examines the relationship between livestock production, which is equivalent to human benefit within the context of his article, and perceived welfare, which is equivalent to animal benefit. He portrays this relationship through a production curve. The curve begins with Point $\mathrm{A}$, at minimal livestock production and a natural welfare starting point where no effort goes towards managing the animal's production (McInerney, 2004). Point B depicts a slightly higher livestock production rate, as well as a higher welfare rate that represents the efforts to protect an animal from predators and to feed and house animals (McInerney, 2004). Beyond this point, animal welfare begins to decrease and livestock production continues to increase (McInerney, 2004). The author point outs that individuals identifying as vegans/vegetarians may select Point A as the ideal welfare position (McInerney, 2004). However, he states that while this may be the most ethical position, it does not acknowledge commercial livestock needs (McInerney, 2004). McInerney (2004) argues that a third point, with slightly lower animal welfare levels and higher livestock productivity than Point B, may be more idealistic. This third point represents a compromise on behalf of potential livestock productivity for slightly improved animal welfare levels. He points out that current farming practices have most likely moved beyond that third point into even worse animal welfare levels (McInerney, 2004). It is crucial for government to determine the approximate point that farming practices are at on the curve and develop policy options to bring farming practices back to the ideal Point $\mathrm{C}$.

Smith et al. (2005) address an interesting factor to consider when assessing animal welfare policies. They examine the global reality of the meat and animal product industries. Smith et al. (2005) suggest that industries related to animal products should maintain trust with their consumers by ensuring that standards, including animal welfare standards, are met within their production chain. This includes providing consumers with the necessary information to make guided decisions. Smith et al. (2005) note that many consumers are demanding to know more about the origin and traits of the products they are purchasing. Although these consumers probably do not include vegans/vegetarians since they do not purchase animal products, there is still a demand for globally accepted standards when it comes to the animal production industry. It is safe to say that ethical vegans/vegetarians would like to improve animal welfare internationally, but especially within the production chain of their own 
country.

Lusk (2011) suggests that although animal welfare policies can stem from ethical or moral grounds, analyzing the economical aspect of the relationship between animal welfare policies and consumers (e.g. vegetarians and/or vegans) is vital when considering different types of policies. He states that animal welfare is often viewed as an externality, that is when a third party, not directly involved in the transaction, is impacted. Lusk argues that animal well-being should be considered in the utilitarian calculation of policies (2011). He further emphasizes this by briefly explaining the meat production process. Farmers acquire animals to produce meat, then they deal with two types of consumers. Lusk categorized type 1 being the consumers who are carnivores and are only concerned about meat consumption, and type 2 being consumers who are compassionate carnivores and care about animal welfare (2011). It is the interactions and relations between these entities that determine policies regarding meat products. However, farmers also produce another output, besides meat, that is animal welfare. If animal welfare is worsening, this generates a negative externality. This negative externality has a cost on the compassionate consumer, as well as a third type of consumer: vegetarians and vegans. The failure of producers to consider these types of consumers may result in the overproduction of animal products.

Lusk suggests three policies that have been previously proposed to address the animal welfare externality argument:

\subsubsection{Pigovian Tax}

This idea involves taxing meat in order to offset the social cost of production (2011). People for the Ethical Treatment of Animals (PETA) has supported this idea by selling merchandise such as tote bags and t-shirts with the slogan "Tax Meat" (Lusk, 2011). A tax would not only offset the social cost, but also may reduce meat consumption in general, which would reduce animal suffering. However, this policy is susceptible to the idea that it would reduce the quantity of animals affected by the meat industry, but not the quality. Therefore, without other policy changes, the Pigovian tax may just result in the animal be reallocated to another industry.

\subsubsection{Amendments to Processing}

Animal rights groups such as the Humane Society of the United States (HSUS) and the Farm Sanctuary have advocated for legislation to be enacted regarding certain production processes (Lusk, 2011). An example is HSUS's advocacy work to legislate a ban against using veal crates. This type of policy instrument targets the problem at its core and focuses on the relationship between farmers and animals, rather than bringing consumers into the equation. This policy, however, does not ensure the improvement of animal welfare. Many legislations that are passed do not include alternative solutions to the banned practices. This often results in farms finding loopholes to continue their practices without substantially reducing animal suffering. For instance, after HSUS succeeded in its advocacy efforts to ban the use of cages in egg production in California, a farm called J.S. West Incorporated installed larger cages to meet the legislation criteria: which is that animals should have room to completely extend their limbs (Lusk, 2011). 


\subsubsection{Labeling}

This policy entails Labeling certain meat products as being produced with animal welfare in mind. Thus, consumers are able to distinguish the products and purchase according to their own moral grounds. One of this policy's shortcomings is that it addresses only one type of consumer: the compassionate consumer.

\subsubsection{An Animal Welfare Market}

Lusk proposes another policy option, which is to develop a separate market for animal welfare (2011). He argues that the labelling policy pairs up two products, meat and animal welfare, into one (2011). By doing so, policymakers are preventing vegetarians/vegans from influencing the meat industry since they may be left out of policy calculations if they are not being considered as consumers. Lusk states that animal welfare is an output of farmers, but one that does not have a price and so farmers do not have an incentive to produce more of. He suggests offering farmers property rights over animal-welfare in the form of Animal Well-Being Units (AWBUS) that can be independently sold and bought (2011).

\section{Discussion \& Critical Review}

The findings show that while there is an evident relationship between veganism/vegetarianism and animal welfare policies, it is difficult to determine the direction of this relationship. In other words, there is no clear indication whether the stronger impact lies with veganism/vegetarianism influencing the direction of animal welfare policy or whether animal welfare policy direction influences individuals' eating choices. Janssen et al. (2016) found that the majority of their interview participants indicated that animal-related reasons influenced their decisions to become vegan. Moreover, Fox (2013) suggested that even if animal welfare was not the main driver for following a plant-based diet, ethical concerns usually develop later on, particularly for vegans since they follow a stricter diet than vegetarians. On the other hand, Herzog et al. (2009) made the interesting finding that half of the participants who identified as vegetarians did not identify as animal activists. This shows that although individuals may choose to follow a vegan/vegetarian diet for animal welfare reasons, they may not have enough of an active role in society to actually impact policy. This is important to acknowledge because typically policy influence and change occurs through solidarity. In other words, solidarity provides legitimacy to movements. If there is a lack of solidarity amongst vegans/vegetarians, then this will undermine their power as consumers and as influencers of policy.

One fact appears to be clear and that is the increasing trend of veganism/vegetarianism. Consumers are not only becoming vegans/vegetarians, but meat-eaters are also reducing their meat and animal-product intake in general (Faculty of Management, 2013). The increase of vegans/vegetarians may also result in an increase awareness of farm animal welfare practices. Furthermore, the younger generations are more likely to be vegans/vegetarians than older generations (Flanagan, 2018). This indicates a future trend regarding consumers' purchase of animal products and their views on welfare. As a result, industries pertaining to animal 
products will be faced with a challenge. Demands for animal products may decrease in the future. It is crucial for these industries to assess their relationship with consumers. For instance, food retailers may want to demand higher animal welfare standards from suppliers in order to improve their branding and attract more customers. The survey by Bennett (1997) mentioned how $61 \%$ of respondents avoided or purchased specific animal products because of their concern about animal welfare. Furthermore, vegan/vegetarian consumers and the increasing trend of veganism/vegetarianism may influence compassionate consumers to substitute their animal products with plant-based products. Food innovations such as beyond meat have allowed meat-eaters and vegans/vegetarians to access protein-filled and meat-tasting plant-based products (Bonnet et al., 2020). Thus, if animal product industries and policymakers fail to consider the impact of veganism/vegetarianism on animal welfare awareness, then an overproduction of animal products may occur.

\section{Limitations}

One major limitation to assessing the impact of veganism/vegetarianism on animal welfare policy is that their motives may change over time. The review above has shown that animal welfare is not the only reason that individuals opt for a plant-based diet. There are other reasons as to why individuals choose to follow a plant-based diet and these reasons may change over time as an individual changes. For instance, many vegans/vegetarians choose to follow their diets for environmental and sustainable reasons. It is difficult to develop food policies without understanding the end-beneficiaries' goals. However, this limitation be may be reduced by including vegan/vegetarians in the formation process of animal welfare policies. As mentioned in the literature review above, many of the animal welfare codes are developed to standardize industries rather than improve animal-wellbeing and rights. Another limitation is highlighted in the article by Herzog et al. (2009), which found that not all vegans/vegetarians are activists. This illustrates that it may not be veganism/vegetarianism itself that influences animal welfare policies, but the moral intuition behind individuals.

\section{Conclusion and Future Directions}

Although it is not clear whether veganism/vegetarianism actively impacts animal welfare policy, it is evident that the popularity of such diets will inevitably impact popular culture and consumer attitudes regarding animal welfare. As a result, animal product industries will be negatively impacted and may need to improve animal welfare standards. After analyzing the literature around plant-based diets and farm animal welfare policies, it became apparent that there is a lack of studies that focused on the direct relationship between veganism/vegetarianism and farm animal welfare policies. Instead, many studies made a relation between veganism/vegetarianism and sustainability and environmental policies. Future research can focus on analyzing the direct relationship between vegans/vegetarians and welfare policies. Moreover, it would be noteworthy to examine the impact on animal welfare policies beyond borders. In other words, how will animal welfare standards be met and extended throughout the entire production process, which may include cross-border transportation. Finally, another area of focus can be around analyzing Canadian animal-welfare policies and codes in detail to determine the level of animal welfare according 
to McInerney's production curve (2004). This is important because animal welfare can be defined differently by different individuals, so it is crucial to identify a common level of animal welfare that is currently taking place in Canada. Analyzing the level of animal welfare maintained in Canada can aid future conversations with vegans/vegetarians and animal activists to develop improved animal welfare policies.

\section{Bibliography}

Bennett, R. M. (1997). Farm animal welfare and food policy. Food policy, 22(4), 281-288. https://doi.org/10.1016/S0306-9192(97)00019-5

Bradley, A., \& MacRae, R. (2011). Legitimacy \& Canadian Farm Animal Welfare Standards Development: The Case of the National Farm Animal Care Council. Journal of Agricultural and Environmental Ethics, 24(1), 19-47. https://doi.org/10.1007/s10806-010-9240-z

Bonnet, C., Bouamra-Mechemache, Z., Réquillart, V., \& Treich, N. (2020). Regulating meat consumption to improve health, the environment and animal welfare. Food Policy, 101847. https://doi.org/10.1016/j.foodpol.2020.101847

Charlebois, S. (2018). The Conversation: Young Canadians Lead the Charge to a Meatless Canada. Dalhousie University. Retrieved from https://www.dal.ca/news/2018/03/16/theconversation-young-canadians-lead-the-charge-to-a-meatless-c.html

Faculty of Management. (2018). Release: New Dalhousie study finds that 6.4 million Canadians limit the amount of meat they eat, and number will likely grow. Dalhousie University. Retrieved from https://www.dal.ca/faculty/management/news-events/news/2018/10/30/ release_new_dalhousie_study_finds_that_6_4_million_canadians_limit_the_amount_o f_meat_they_eat_and_number_will_likely_grow.html

Flanagan, R. (2018). More than 3 million Canadians vegetarian or vegan: study. CTV News. Retrieved from https://www.ctvnews.ca/canada/more-than-3-million-canadiansvegetarian-or-vegan-study-1.4027606

Fraser, D. (2001). Farm animal production: changing agriculture in a changing culture. Journal of Applied Animal Welfare Science, 4(3), 175-190. https://doi.org/10.1207/S15327604JAWS0403_02

Fox, M. A. (2013). Vegetarianism and veganism. International Encyclopedia of Ethics. https://doi.org/10.1002/9781444367072.wbiee009

Government of Canada. (2020). List of acts and regulations. Retrieved from https://www.inspection.gc.ca/about-the-cfia/acts-and-regulations/list-of-acts-and-regulati ons/eng/1419029096537/1419029097256

Herzog, H. A., \& Golden, L. L. (2009). Moral emotions and social activism: The case of animal $\begin{array}{lllll}\text { rights. Journal of } & \text { Social }\end{array}$ https://doi.org/10.1111/j.1540-4560.2009.01610.x 
Ingram, D. (2017). National aspirations, governance networks and the development of Canada's animal welfare movement/Aspirations nationales, réseaux de gouvernance et le développement du mouvement de protection des animaux au Canada. British Journal of Canadian Studies, 30(1), 91-I. https://doi.org/10.3828/bjcs.2017.5

Janssen, M., Busch, C., Rödiger, M., \& Hamm, U. (2016). Motives of consumers following a vegan diet and their attitudes towards animal agriculture. Appetite, 105, 643-651. https://doi.org/10.1016/j.appet.2016.06.039

Jallinoja, P., Vinnari, M., \& Niva, M. (2018). Veganism and plant-based eating: Analysis of interplay between discursive strategies and lifestyle political consumerism. In The Oxford handbook of political consumerism. Oxford University Press Oxford. https://doi.org/10.1093/oxfordhb/9780190629038.013.52

Lusk, J. L., \& Norwood, F. B. (2011). Animal welfare economics. Applied Economic Perspectives and Policy, 33(4), 463-483. https://doi.org/10.1093/aepp/ppr036

Lusk, J. L. (2011). The market for animal welfare. Agriculture and Human Values, 28(4), 561-575. https://doi.org/10.1007/s10460-011-9318-x

McInerney, J. (2004). Animal welfare, economics and policy. Report on a study undertaken for the Farm \& Animal Health Economics Division of Defra, 68. (ECON)

Smith, K. R., Clayton, P., Stuart, B., Myers, K., \& Seng, P. M. (2005). The vital role of science in global policy decision-making: An analysis of past, current, and forecasted trends and issues in global red meat trade and policy. Meat science, 71(1), 150-157. https://doi.org/10.1016/j.meatsci.2005.04.007

\section{Copyright Disclaimer}

Copyright for this article is retained by the author(s), with first publication rights granted to the journal.

This is an open-access article distributed under the terms and conditions of the Creative Commons Attribution license (http://creativecommons.org/licenses/by/4.0/). 